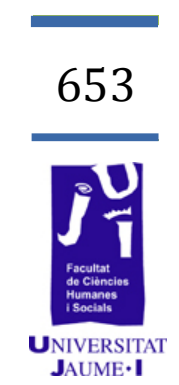

\title{
Más allá del lenguaje: los aerolitos de Carlos Edmundo de Ory
}

J. Rafael Mesado Gimeno rafamesado@hotmail.com 
Los aerolitos son segmentos lingüísticos breves e intensos, a modo, de sentencias y aforismos, que presentan, desde un significante inconexo y desde un significado paradójico, un instante de lucidez. José Ramón Ripoll (2011: 205) señala la impronta radiante, luminosa y vívida de los aerolitos:

Ory llamaba aerolitos a esos fugaces instantes de conciencia representados por frases inconexas que, desde el espacio caótico del pensamiento, caen sobre el papel tras un viaje milenario. Son formas perdidas del sueño, experiencias acumuladas de lecturas, luces de la observancia que van configurando en su esparcimiento el extraordinario apriorístico de su poesía.

Los aerolitos oryanos se hallan contenidos en varias obras y, también de modo disperso, en otras publicaciones como revistas y antologías. Los primeros aerolitos se publicaron en francés en el año 1962 con el título de Aèrolithes y acompañados de un prólogo de Michel Béalu. También en francés y en versión del propio autor apareció en 1966 otra publicación de los aerolitos en la revista Réalités Secrètes, titulada también Aèrolithes. Las dos publicaciones francesas se editaron en castellano en la revista Cuadernos Hispanoamericanos, la primera en $1965^{1}$ y la segunda en $1969 .^{2}$ En 1985 , tal y como queda indicado en la bibliografía, los aerolitos se publicaron en castellano en forma de libro en la editorial El Observatorio con el título de Aerolitos. Algunos de estos ya habían aparecido en 1970 en la antología oryana realizada por Féliz Grande, Poesía 1949-1969 y en 1978, recogidos por Rafael de Cózar, en la antología Metanoia, ampliada en 1991. Posteriormente han aparecido dos ediciones más en la editorial Calambur, una en 2005 y otra en 2011, prologada por Félix Grande. En 1995 Ory publicó un nuevo grupo de aerolitos bajo el título de Nuevos Aerolitos y en 2009 otra entrega más: Novísimos Aerolitos. En la antología realizada por Jaume Pont y editada en 2003, Música de lobo. Antología poética (1941-2001) aparece una breve selección de los aerolitos y en la antología-homenaje a Ory realizada en 2006, El desenterrador de vivos, se publican varios aerolitos inéditos. Por otra parte, fragmentos de lo que son los aerolitos han aparecido en otras publicaciones. ${ }^{3}$

Pont (1998: 308-309) encuentra los antecedentes de los aerolitos en la literatura postista, lúdica y experimental: las pulgas, los emblemas y los ejercicios de enderezamiento aparecidos en las dos revistas que editó el Postismo en 1945, Postismo y La Cerbatana. Las pulgas y los emblemas, al tratarse de frases breves y lacónicas, son relevantes por su brevedad y su

1. Núm. 181, enero, Madrid, 1965.

2. Núm. 230, febrero, Madrid,1969.

3. Alcance, núm. 9, León, 1981; Barcarola, núm. 15, Albacete, 1984; Hora de poesía, núm. 50-51, Barcelona, 1987; Diario de Cádiz, abril, 1993; Cuadernos Hispanoamericanos, núm. 545, Madrid, 1995; El ciervo, núm. 544-545, Barcelona, 1996; La carátula, separata, Elche, 1998; Caleta, núm. 2, Cádiz, 1998; RevistAtlántica de Poesía, núm. 27, Separata dedicada a Ory, Cádiz, 2004. 
impetuosidad. El enderezamiento, técnica intertextual mediante la que aplicando mínimas variaciones se puede modificar el texto de manera infinita, importan por la tarea paródica de subvertir el texto. Pont (1988: 10-11) señala también como un antecedente del aerolito las proposiciones establecidas por Ory en el Atelier de Poésie Ouverte, ${ }^{4}$ aunque estas sesiones, fechadas entre 1967 y 1968, son posteriores a las primeras ediciones de los aerolitos.

\section{Hacia una definición de aerolito}

El propio Carlos Edmundo de Ory ofrece en las ediciones de sus aerolitos (1995: 13; 2005: 7) algunas pistas y referencias acerca del discurso minimal de los aerolitos.

Novalis los llama: polen; Rozanov: hojas caídas; Baudelaire, cohetes; Nietzsche: sentencias y dardos; Antonio Porchía: voces; Louis Scutenaire: inscripciones; Cioran: pensamientos estrangulados; André Siniavski: pensamientos repentinos; Malcom de Chazal: sentido-plástico; yo: aerolitos.

En su diario (2004) Ory teoriza sobre la especificidad del discurso de los aerolitos y plantea, desde su particular mirada poética, algunas definiciones:

Sigo haciendo aerolitos de cuando en cuando, cuando me viene la chispa. Son perlas del cráneo llenas de corazón. A veces no tengo tiempo de trasladar a mi Diario los trozos sueltos de texto que escribo con una finalidad temática, y luego no utilizo dejándolos desunidos. Mejor reunirlos en archipiélago, como islitas en el mar de la escritura (2004, Vol. III: 185).

Resulta muy interesante la definición que ofrece su autor: «son perlas del cráneo llenas de corazón». Discurso psicosomático, integrador de la totalidad del ser humano, sin escisiones entre cuerpo y mente, que conecta el discurso cerebral, cuyo signo es el concepto, con la visceralidad propia del discurso de la emoción. El aerolito oryano, cuyo referente más alejado se encuentra en la literatura gnómica medieval, se distingue de la máxima y del aforismo en el rechazo del concepto como único punto de interés. No es un puro artefacto conceptual, simple labor de orfebrería inteligible; el aerolito surge de la emoción, del sentimiento y de la experiencia interior. Es un breve paisaje de la interioridad lanzado como un rayo, que ilumina en la noche, hacia el exterior. El aerolito rehúye el discurso intelectual y se sitúa como discurso periférico. Discurso poético, visceral, emocional, onírico, absurdo, paradójico, lúdico, metafísico. En el Diario de Ory encontramos diversas calves que pueden acercarnos a una definición del aerolito: 
Quintaesenciar, ser elíptico, discontinuo. Saltos, digresiones. Decir lo indecible: balbucir.

Economía verbal extrema. No verbalización. Gnómica, haikú. Mejor que nada: el silencio. La sentencia wittgenstiana: «De lo que no se puede hablar hay que callar» (2004, Vol. III: 273).

El discurso salta, liberado de la tiranía de una semántica que lo

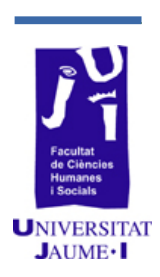
atrapa, en el vacío, como los fuegos artificiales iluminan la noche. En este sentido, es un relámpago de luz, símbolo del satori en el budismo zen, que estalla en la mente lectora. Ory instala los aerolitos en la poética del silencio y los compara con la estética del haiku budista. Son fragmentos mínimos del lenguaje del silencio, para ello Ory cita las palabras de Wittgenstein que cierran el Tractatus logico-philosophicus (1921). Los aerolitos no son máximas, sino mínimas, pequeñas islas en el mar del discurso. Como las palabras, que son islotes que sobresalen en el océano del silencio, representado por la luz del blanco de la página.

Ory va ofreciendo las referencias precisas de sus aerolitos: Novalis, Nietzsche, Heidegger, Kafka, Breton, Friedrich Hebbel... Pero los aerolitos son herederos de la dislocación discursiva de la vanguardia, del dadaísmo, del surrealismo... Son herederos de las afiladas declaraciones de los manifiestos de Tistan Tzara o de André Breton. Por ello las greguerías de Ramón Gómez de la Serna resultan una referencia muy especial debido al juego lingüístico, al componente lúdico, al humorismo inteligente, a la ruptura semántica y a la incongruencia. La presencia de la greguería en la poesía oryana viene de lejos, se efectuó en los años del Postismo. ${ }^{5}$

De hecho algunos aerolitos oryanos presentan evidentes similitudes con las greguerías. La estética postista se plegaba perfectamente sobre la

\footnotetext{
5. Resulta paradójico, pero Gómez de la Serna cita a Ory como uno de los herederos de las greguerías. Así lo testimonia el siguiente fragmento del Diario de Ory: Ver el artículo «Releo el Diario de Friedrich Hebbel, en una edición italiana de 1912, que poseo desde abril de 1954 desde entonces uno de mis libros de cabecera, y un espejo de aforismos semejantes a mis Aerolitos.

Leí uno que dice: L'odore e la morte del fiore.

Es un «aerolito» o una "greguería». Y veo que lo cita Ramón Gómez de la Serna en su prólogo a la sexta edición de sus Greguerías / selección 1910-1960, publicado en colección Austral, en febrero de 1960. Traducida al español, así como otras perfectas "greguerías» del poeta y dramaturgo alemán, continúa citando autores de todos los tiempos (que greguerizan): «...y las de Hebbel: el perfume es la muerte de las flores, o Las pulgas son los únicos animales que no tienen pulgas, o El hombre únicamente está en éxtasis cuando reza y cuando de afeita.»

Y también cita -ino me lo esperaba!- «entre los buenos gregueristas de última hora», cosas de Jacinto Miquelarena y mías, que no sé de dónde las sacara por permanecer inéditas y hasta olvidadas por mí: "Son buenas las de Edmundo de Ory: "El silbido es el esqueleto de la palabra», "La luna es la cáscara del silencio del mundo», "El acordeón de la semana se rompe siempre los domingos».

Cita estos tres ejemplos de mi cosecha ramonesca, de los años del Postismo, cuando yo acudía a la tertulia del Café Pombo, en la calle Carretas, los sábados por la noche. Fui asiduo de la Sagrada Solana Cripta Pombo, pero sin Ramón» (y 2004, Vol. III: 315).

En la Historia del postismo, escrita por Ory y publicada en la antología que realizó Félix Grande en 1970, aparece también la misma referencia: «En cuanto a Ramón, él hubiera saludado el Postismo sin duda alguna. Lo hubiera saludado por encima o por debajo de su ramonismo. Ya en la selección que hizo de sus GREGUERÍAS (1010-1960), en la Colección Austral, pude ver que me saluda personalmente en la página 41 al pasar revista a sus coríferos: "Son buenas las de Edmundo de Ory: "El silbido es el esqueleto de la palabra", "La luna es la cáscara del silencio del mundo", "El acordeón de la semana se rompe siempre los domingos", y las del escritor argentino Gotardo Croce» (1970: 267-268).
} 
impronta ramoniana. La risa, el juego y la estridencia pueden observarse perfectamente en los siguientes aerolitos:

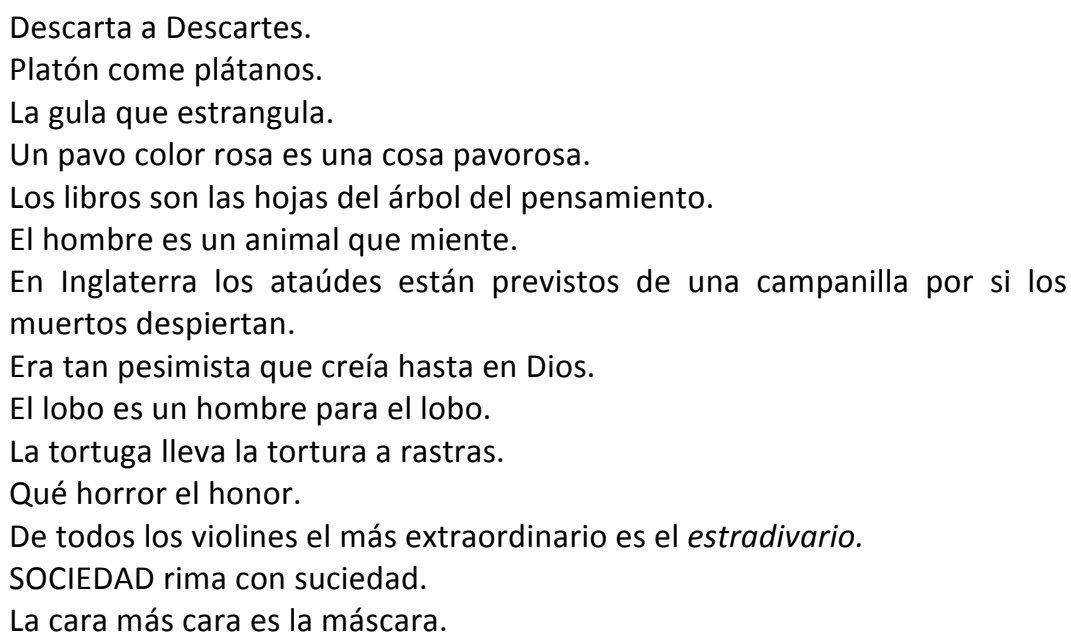

La experimentación lingüística es el signo de este lenguaje dislocado, en el que la proximidad fónica articula los signos, sacudiendo la coherencia y la referencialidad. De otro lado, el humor, que surge del enfrentamiento de los significados, es el eje central hacia el que gravita este lenguaje deshilvanado. Lenguaje que se basa en la significación periférica de las palabras y atiende a un significado profundamente emocional, basado en la plurisignificación, en las resonancias connotativas despegadas del significado central denotativo (calambur, retruécano, paranomasia, metáfora...). Juego y deformación del significado. Las siguientes greguerías de Gómez de Serna ${ }^{6}$ podrían perfectamente pertenecer a Ory:

\section{El minotauro de minutero.}

¿Cuál es la mujer más antigua? Antígona.

Descartes: es el que se descartó de muchas ideas para quedarse sólo con las buenas.

Mentor parece ser el que enseña a decir mentiras.

No sólo el juego, el humor y la experimentación son los ingredientes que definen el aerolito, este se configura como un instante de iluminación, como un rayo nocturno que alumbra los paisajes mentales más ocultos y despeja las sombras para que nuevos significados surjan de sus escondites. Los aerolitos oryanos tratan desde cuestiones puramente metapoéticas hasta las metafísicas, pasando por referencias sociales, culturales, religiosas... En ellos Ory desvela su pensamiento, muestra claramente sus referencias y ofrece su punto de vista particular hacia los autores citados, óptica que en algunos casos supone apropiaciones e identificaciones $\mathrm{y}$ en otros exclusiones $\mathrm{y}$ ataques. Los aforismos siguientes, que pertenecen al pensador escéptico y pesimista por 
excelencia, E. M. Cioran, poseen un regusto oryano. Ambos autores se acercan a la paradoja, al contraste y a la oposición:

Cada ser es un himno destruido.

Estamos todos en el fondo de un infierno, cada instante del cual es un milagro. ${ }^{7}$

La definición de los aerolitos, en todo caso, se encuentra en uno de ellos. Ory nos la ofrece en esta frase, lapidaria como una pedrada:

La poesía es un vómito de piedras preciosas.

Poesía como operación visceral diamantina, como alquimia digestiva o etílica. Si la poesía es joya, lo es también el aerolito: una perla de sabiduría.

\section{Identificaciones y exclusiones}

En los aerolitos Ory va estructurando las coordenadas de su particular viaje cultural. Estos, junto a sus ensayos y su Diario, son el cuaderno de bitácora que ofrece la cartografía del extraño laberinto por el que Ory transita. Los aerolitos se configuran como tarea de meditación y de reflexión sobre un territorio temáticamente acotado que responde a las preocupaciones de su autor: metapoesía, metalenguaje, cultura, simbología, metafísica... En ellos Ory ofrece su mirada sobre el estado de las cosas y ofrece acercamientos al misterio inefable de la existencia.

Ory muestra sus cartas boca arriba y son ellas las que definen su ideario plegándose sobre las referencias ofrecidas. Los aerolitos funcionan como un mapa mental que estructura el territorio mediante una señalización emocional. Son, pues, una vía de acceso intuitiva a la realidad, un acercamiento poético a la existencia.

El aforismo, por sí mismo, posee siempre una carga poética que lo erige, por condensación, en una alquimia de la palabra. Comparado con el discurso narrativo e informativo, el aforismo, como el lenguaje poético, consiste en una palabra vehemente, de alto octanaje. En este sentido, José Antonio Marina (2003: 10) señala en el prólogo a la obra que recopila los aforismos dispersos de Max Aub, Aforismos en el laberinto, que los aforismos «suponen a veces un aerolito de poesía en el campo de la prosa». Ofrecemos aquí unos aforismos de Aub que tienen evidentes paralelismos con los aerolitos oryanos:

Dejar y no dejarse.

Ser molino y no molienda.

Primero fue el silencio.

Todo está por hacer: hagas lo que hagas, nunca se hizo. ${ }^{8}$

7. Aforismos pertenecientes a El aciago demiurgo (1969), tomados de la antología realizada y prologada por Fernando Savater: Adiós a la filosofía y otros textos, Alianza Editorial, Madrid, 1998, p. 161, p. 162.

8. Aub, Max (2003): Aforismos en el laberinto, ed. de Javier Quiñones, Barcelona, Edhasa. 
Escritura ideológica donde el lenguaje se abre ante el lector mostrando sus resquicios significativos ocultos. Los aerolitos de Ory van cargados de un potente significado oculto, en ocasiones corrosivo, que hace de esta escritura un texto ideológicamente pregnante, tal y como ocurre en los siguientes aerolitos:

El Hombre de Damasco (Pablo). El hombre vestido de damasco.

Existencia oficial del infierno (concilio de 547).

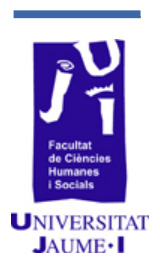

La lluvia, del cielo para abajo, no moja a Dios.

Los besos: pecados mortales (Padres de la Iglesia).

Los aerolitos de Ory suponen verdaderos ataques a los sistemas opresivos del ser humano, a sus creencias y a sus prácticas. Existen en ellos diatribas contra la explotación material y mental del hombre. Entre los símbolos culturales rechazados se encuentran: San Lucas, San Juan Evangelista, San Mateo, San Agustín, San Pablo, Aristóteles, Descartes, Pascal, Leibniz, Kant, Hegel, Tolstoi, Hitler, Franco, Lenin, Stalin... Así Ory acerca su discurso al pensamiento libertario y erige la heterodoxia como símbolo cultural:

De mis listas de gente interesante: idiotas, enanos, monstruos, payasos, apaches, vagabundos, gitanos, harapientos, amerindios, esquimales, beduinos, lapones, bobos, ufólogos, insumisos.

Mi patria es el aire que respiro.

Los dardos de Ory apuntan a la misma diana que las afiladas sentencias de Friedrich Nietzsche: al cristianismo cuyos valores fueron los supuestos en los que se edificó la decadence:

Se ha observado mal la vida, cuando no se observa la mano que, con todos los respetos, mata...

En tiempo de paz, el hombre belicoso se hace la guerra a sí mismo.

No amar más que a uno solo es una forma de barbarie, pues va en detrimento de todos los demás. Así el amor a Dios. ${ }^{9}$

Una decisión peligrosa. La decisión cristiana de encontrar un mundo feo y malo ha hecho un mundo feo y malo. ${ }^{10}$

Como Nietzsche, Ory no sólo ataca al cristianismo como método de subyugamiento, sino también a su sombra, el racionalismo y sus derivaciones políticas: los totalitarismos, tanto de signo capitalista como comunista:

CONCIENCIA comunista: Prohibido el inconsciente en la sociedad soviética. Maud Tabachik, escritora israelita, atormentada por el recuerdo del Holocausto: "Hitler fue seguramente un chiquillo encantador. Pol Pot, también».

9. Nietzsche, Friedrich (1886): Más allá del bien y del mal, traducción de Carlos Vergara, EDAF, Madrid, p. 93. 10. Nietzsche, Friedrich (1882): La gaya ciencia, traducción de José Mardomingo Sierra, EDAF, Madrid, p. 215. 
Otras referencias, contra las que se recorta de manera positiva la geografía cultural oryana son: Diógenes, Heráclito, Montaigne, Spinoza, Hölderlin, Goethe, Flaubert, Nietzsche, Heidegger, Kierkegaard, Thoreau, Baudelaire, Rimbaud, Poe, Kafka, Whitman, Valéry, Freud, Jung, Breton, Benjamin Péret, Eluard, Artaud, Wittgentein, Jorge Guillén, Juan Ramón Jiménez, Lorca, Maiakovsky, Céline, Cioran, Nabokob, Ernest Jünger, Bernanos, Bachelard, Koestler, Hebbel, Pavesse, César Vallejo, Konrad Lorenz, Thomas Merton, Krishnamurti, Ginsberg, Castaneda, Malcom Lowry, Lyotard, Lipovetsky... Ory sigue a través de la brecha abierta por Nietzsche y transita recorridos más allá de la dogmática establecida por el conocimiento científico y por el pensamiento sistemático. Se sitúa pues en las coordenadas de un pensamiento borroso que intenta aprehender un realidad líquida y flexible, continuamente dinámica, donde los límites que encierran los conceptos y entidades no quedan precisados con rigidez. El diario oryano nos lo aclara con más nitidez (2004, Vol. III: 286):

Más allá del dominio del conocimiento científico, existe el vasto campo de lo incognoscible y de la nesciencia, desde siempre explorado por la metafísica y por la religión de los misterios. Un más allá que los positivistas llaman «inmensidad» y Freud "sentimiento oceánico», que se apodera del espíritu y lo sumerge.

Los aerolitos muestran vislumbres y resplandores, a modo de instantáneas, de esa zona abierta que desemboca en la metafísica y en el misterio existencial. "Aforismos del espíritu libre» los denomina Ory en el diario (2004, Vol. III: 286) cuya función es desvelar territorios ocultos por la sombra de la razón (2004, Vol. III: 288):

Frases anormales, ondeantes y versátiles, cuanto más ilógicas más mágicas.

Contra el lenguaje tradicional y la palabra declamatoria, registro de ensueños y de reflejos infinitos, comunicando tonos privativos de la imaginación y del inconsciente.

Citamos aquí varios ejemplos:

La luna es una obra maestra.

El tiempo es la respiración del espacio.

Con mis manos llenas de curiosidad toco el insecto de lo desconocido.

Chocamos contra el muro del infinito.

Llueve luego existo.

Dios está en la sal y en el azúcar.

El cosmos no oye la campana de la iglesia llamando a oración. En cambio, oye el zumbido de un mosquito o el roer de un ratón.

Los huesos de la respiración.

Ama la lluvia como a ti mismo.

Se dice el más allá, pero nunca decimos el más aquí. 
IV. Más allá del lenguaje

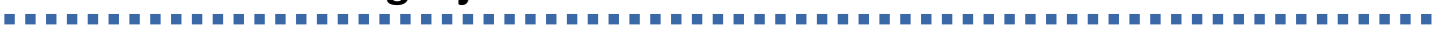

La poesía oryana supone un proceso de meditación, la búsqueda de un lenguaje que pueda trascender el pensamiento racional y la referencialidad pragmática (Mesado, 2014: 83-84). Ory busca en el pensamiento del budismo zen, en su lenguaje terriblemente disparatado y absurdo, pero cargado de evocación, la transgresión del pensamiento lógico. En este sentido, el koan ofrece una fractura lingüística que nos hace saltar más allá del pensamiento. El koan hace estallar el lenguaje porque supone una situación sin salida. Busca la experiencia directa, la fluidez inmediata, la ocurrencia repentina, la clarividencia del gesto. El koan se dirige a la realidad y no al pensamiento. Se dirige al silencio mediante la ruptura del lenguaje. Se trata de la supresión del pensamiento, tal y como ocurre en la meditación zazen.

En el budismo zen japonés se dan dos direcciones: la escuela rinzai y el soto zen. El zen rinzai utiliza el koan como método de ayuda para alcanzar el satori en el proceso de la meditación, samadhi. El zen soto, en cambio, rechaza el uso del koan por considerarlo un soporte artificial en el proceso de búsqueda de la iluminación. Para esta escuela, la práctica del zazen es la única vía posible para llegar al satori. De todas formas, el koan impregna todo el pensamiento budista, extraño, paradójico y absurdo. En la literatura zen existen diversas colecciones de koans, en otras ocasiones el koan se ofrece en una situación o en un diálogo ${ }^{11}$. El monje Nansen cuando su maestro iba a partir con su sable un gato por la mitad, objeto de una disputa de los monjes del monasterio, se puso los zapatos sobre la cabeza. Otro monje visitó a Basho para preguntarle cuál era el principio del budismo y Basho le pego como repuesta. Existen algunos famosos koan como los que siguen:

Dime cual es el sonido de una sola mano (Hakuin, 1685-1768).

¿Cuál es el rostro que tenías antes de nacer? (Hui.Neng / Eno, 683-713).

¿Un perro tiene la naturaleza de Buda? (Joshu Jushin / Chao-Chou, 778897).

El lenguaje de silencio de la poesía oryana está más próximo al koan que al haiku, toda ella está atravesada por la lógica paradójica del koan. La poesía postista supuso una semántica ilógica, lúdica, extraña y absurda que desembocó en el arte conceptual de los aerolitos. Si la poesía del haiku es como la reverberación de las ondas creadas al caer una piedra en un estanque, los aerolitos son como pedradas a la cabeza, relámpagos en la noche que súbitamente iluminan. Ellos intentan subvertir las coordenadas que estructuran nuestro pensamiento, su impronta es abrir brechas para que el pensamiento opere en nuevas direcciones. Los aerolitos son chispas que provocan un incendio cerebral, plantean un impasse en nuestras rígidas y acomodaticias estructuras mentales que propone un salto mental, un juego que apunta a la terrible paradoja que

11. Ver Cleary, Thomas (1993): Cien historias de iluminación, traducción de Sebastián Vázquez Jiménez, EDAF, Madrid, 1995. 
supone el propio lenguaje. Como apunta Alan Watts (1958: 23-24) en la frase "qué le ocurre a mi mano cuando cierro el puño», el lenguaje se desvela incapaz de representar la realidad. La paradoja, como señalaba Zeón de Elea, ${ }^{12}$ únicamente existe en la representación, no en la realidad. Y desvela que la representación no se ajusta a ella. Los aerolitos se acercan al silencio porque destruyen el lenguaje. Al igual que el koan, lo hacen estallar y su fractura crea una explosión que provoca un terremoto cerebral que expande el pensamiento, proyectándolo más allá de las palabras, hacia las cosas. El aerolito apunta hacia la percepción directa de la realidad:

\author{
Di algo que no sepas decir. \\ ¿De qué color es el silencio? \\ Ciegos son aquellos que no ven lo invisible. \\ Nunca cambia de sitio el infinito. \\ Un beso no se describe. \\ El silencio tatuado. \\ En el vacío del aire nada es nada. Nadie ha visto los pensamientos. \\ Ningún esqueleto es metafísico. \\ La muerte no se acaba nunca. \\ Acuérdate de ahora mismo. \\ Sin silencio previo las palabras no suenan.
}

\title{
V. A la estela de los aerolitos
}

Los aerolitos oryanos significan una propuesta poética, teórica y metafísica a la vez, que trasciende el puro juego literario y lúdico. En este sentido, las minimás de la escritora y poeta Carmen Camacho (Alcaudete, Jaén, 1976), ligada a la acción poética y a la interrelación entre la poesía y las artes escénicas, suponen la continuación directa de los aerolitos de Ory. La poesía de Carmen Camacho converge con la poesía oryana en el minimalismo poético que incorpora el lenguaje del silencio, en la libertad que presupone una poesía auténtica y vital, que intenta desvelar los enigmas interiores y aquellos que quedan ocultos en los pliegues de la realidad menos visible, en la ironía de un lenguaje apartado de normativas grupales y de tendencias. Este lenguaje mínimo y naï, expresado en poemarios como Campo de fuerza (2012) o Vuelo domestico (2014), rechaza los artificios para expandir los resortes de la sugerencia. Lenguaje que recupera la antigua oralidad popular, el minimalismo poético y la poética del silencio cercana al haiku.

Las minimás de Camacho, establecidas en la obra Minimás (2008, 2009), son la derivación de los aerolitos de Ory. Entre la greguería y el aforismo, las minimás se acercan al lenguaje de los sueños, a la ingenuidad poética de la infancia, a las anodinas y breves expresiones de la calle, a las pintadas de los muros urbanos, a los cantares de la tradición popular y, como no, a la lógica paradójica del koan. Los siguientes 
fragmentos tienen un sabor totalmente oryano, sin perder la impronta de su autora, sugerente y sensible:

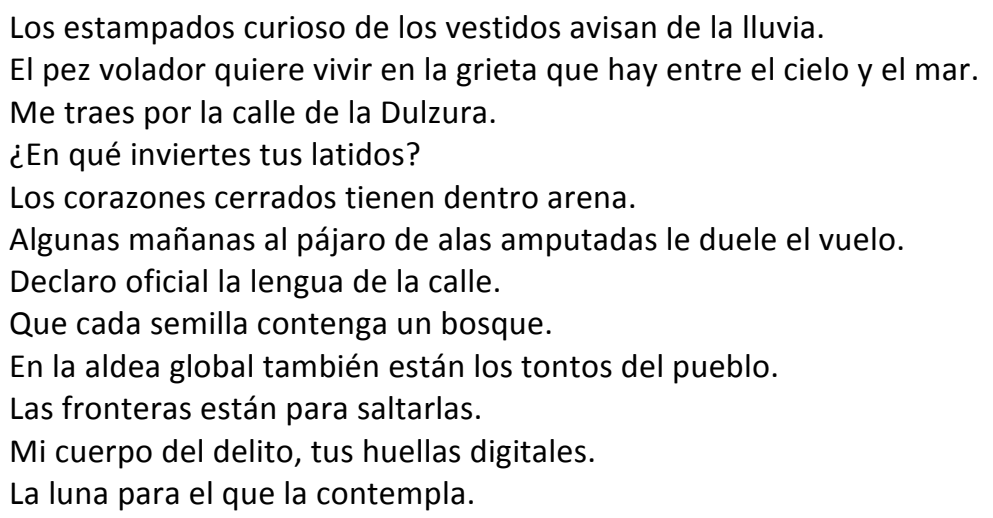

Las minimás sortean el lenguaje comunicativo, sustentado en el significado referencial, para despistar a la lógica e ir más allá, hacia la paradoja. Desde la más radical irracionalidad, ofrecen un chispazo, una llamarada que surge del choque de los conceptos desubicados entre sí en las capas freáticas del paisaje mental. Esta libertad lingüística que las minimás alcanzan supone el origen perdido, aquel que todavía puede hallarse en las asociaciones de los juegos de los niños o en el discurso extraño de los locos. Las minimás de Camacho, contenidas entre lo breve y lo sonoro, agitan en lenguaje desligando los significantes de la tiranía de la razón para acercarlos a una significación basada en la emoción. La intuición, la sorpresa y la sugerencia no son meros juegos de artificio, sino que son los goznes que abren las puertas a lo desconocido, al misterio que se halla en la cotidianeidad más cercana. Por ello, las minimás, como los aerolitos de Ory, se proyectan sobre el espacio de la metafísica. La poesía es el anzuelo que permite pescar en las aguas mágicas de la realidad, la linterna que explora e ilumina la extraña geografía de la existencia, velada a los ojos del supuesto sentido común.

\section{Bibliografía}

CAMACHO, C. (2008, 2009): Minimás, Baile del sol, Tenerife.

CleARY, T. (1993): Antología zen. Cien historias de iluminación, traducción de Sebastián Vázquez Jiménez, EDAF, Madrid, 1995.

Marina, J. A. (2003): "Lectura privada de Max Aub», en QuiÑones, J. (ed.): Aforismos en el laberinto, Edhasa, Barcelona.

Mesado, R. (2014): “Ory: poesía y silencio», en Vela, J. (ed.): Coordenadas, III Jornadas en torno a Carlos Edmundo de Ory, Fundación Carlos Edmundo de Ory, Cádiz.

ORY, C. E. (1962): Aèrolithes, Imprimerie Rougerie, París.

- (1965): Aerolitos, en Cuadernos Hispanoamericanos, núm. 181, enero, Madrid. 
- (1966): Aèrolihtes, en Les Rèalités Secrètes, núm. 28-29, diciembre, París.

- (1969): Aerolitos, en Cuadernos Hispanoamericanos, núm. 230, febrero, Madrid.

- (1970): Poesía 1949-1969, GRANDE, F. (ed.), Edhasa, Barcelona.

- (1970): Metanoia, CózAR, R. (ed.), Cátedra, Madrid.

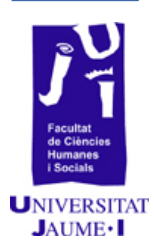

- (1985): Aerolitos (pensamientos y aforismos), El Observatorio, Madrid.

- (1991): Metanoia, CózAR, R. (ed.), Cátedra, Madrid.

- (1995): Nuevos aerolitos, Ediciones Libertarias, Madrid.

- (1991): Música de lobo. Antología poética (1941-2001), Pont, J. (ed.), Galaxia Gutenberg, Barcelona.

- (2004): Diario, 3 Vol., Servicio de Publicaciones de la Diputación, Cádiz.

- (2005): Aerolitos, Calambur, Madrid.

- (2006): El desenterrador de vivos, Galaxia Gutenberg, Barcelona.

- (2009): Novísimos aerolitos, Fundación César Manrique, Madrid.

- (2011): Los aerolitos, Calambur, Madrid.

Pont, J. (1998): La poesía de Carlos Edmundo de Ory, Pagés Editors, Universitat de Lleida.

RIPOLL, J. R. (2011): «El último aerolito (Aerolitos de Carlos Edmundo de Ory)», en Caleta, Literatura y Pensamiento, Segunda Época, núm. 16, octubre, Cádiz.

SuzUKI, D. T. (1959): El zen y la cultura japonesa, traducción de María Tabuyo y Agustín López, RBA, Barcelona, 2002.

WATTS, A. (1958): El camino del zen, traducción de Juan Adolfo Vázquez, Pocket-Edhasa, Barcelona, 1971. 